\title{
Bernd Roeck, Der Morgen der Welt. Geschichte der Renaissance
}

Pierre Monnet

\section{OpenEdition}

Journals

Édition électronique

URL : http://journals.openedition.org/ifha/10575

DOI : $10.4000 /$ ifha. 10575

ISSN : 2198-8943

\section{Éditeur}

IFRA - Institut franco-allemand (sciences historiques et sociales)

\section{Référence électronique}

Pierre Monnet, "Bernd Roeck, Der Morgen der Welt. Geschichte der Renaissance », Revue de l'IFHA [En ligne], Date de recension, mis en ligne le 04 février 2020, consulté le 24 septembre 2020. URL : http:// journals.openedition.org/ifha/10575; DOI : https://doi.org/10.4000/ifha.10575

Ce document a été généré automatiquement le 24 septembre 2020

(C)IFHA 


\section{Bernd Roeck, Der Morgen der Welt. Geschichte der Renaissance}

Pierre Monnet

RÉFÉRENCE

Bernd Roeck, Der Morgen der Welt. Geschichte der Renaissance, München, Beck, 2017, 1336 p., $44 €$ 
L'histoire globale a redonné des couleurs aux grands récits totalisants. Cette somme sur la Renaissance, racontée dans une perspective mondiale qui entrelace l'Europe et les autres aires culturelles, monde de l'Islam et monde chinois en tête, et croise les temps, entre le prétendu Moyen Âge et notre modernité, en livre une preuve supplémentaire. Elle émane qui plus est d'un grand spécialiste de la période: l'auteur est professeur à l'université de Zurich, et, ce qui n'est pas si fréquent dans l'historiographie germanophone, prend le parti d'une narration alerte et captivante sans trop s'encombrer d'un amas de notes de bas de page ( 35 pages de renvois pour 1180 pages de texte, mais un cahier de 50 pages de références bibliographiques) et en réservant une bonne place aux images.
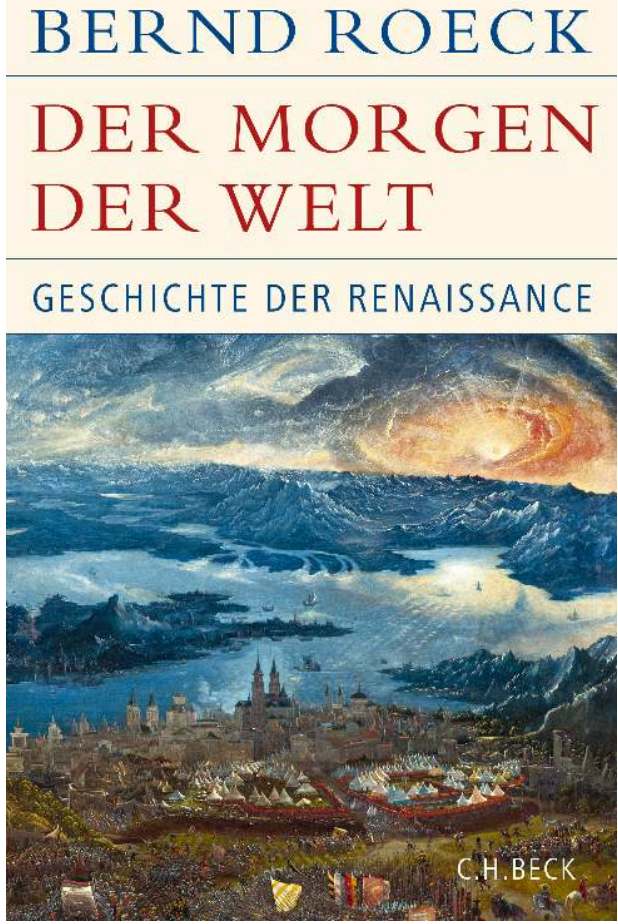

Peut-être est-ce ce choix d'une écriture

sélective, subjective, audacieuse dans ses jugements, qui a pu dérouter les lecteurs et spécialistes allemands. Qu'on en juge dès la première phrase : «Venise, été 1630. Une longue journée tire à sa fin. De la lagune souffle un vent du soir sur les tuiles encore tièdes des toits. » Bien des historiens français se retrouveraient dans une telle entame, ou dans une table des matières qui égrène les titres suggestifs, parfois provocants, comme autant de manchettes de journaux ou d'affiches de films : "printemps arabe ", "Take-off sous le soleil », "femmes puissantes ", " changement climatique ", « la nuit française ", « le papier carbone des États européens ", « l'addiction à Rome », « le matin de la société civile», «le battement d'aile du papillon ", "le soir d'un faune», "le monde, un rêve ", "tristes tropiques " pour ne retenir que les plus savoureux. Mais le livre n'a pas toujours plu et les recensions de la presse comme les comptes rendus des collègues se sont partagés. Il est vrai que le massif impressionne, et parfois déroute, agace même de temps à autre, sans doute le prix à payer d'une histoire totale qui cherche la vérité et le sens d'un «moment » devenu tout à la fois totem, icône, lieu de mémoire.

Aucune partie du monde n'est laissée de côté, comme si l'une des intentions du livre avait aussi été de globaliser Jacob Burckhardt en plongeant l'Europe dans le grand vent pour ramener «sa » Renaissance à ce que l'auteur pense qu'elle fut : un entrelacement d'influences, d'héritages, de modèles parfois jusqu'à l'ultime et indépassable contradiction par laquelle s'achève le livre, à savoir l'Ouest renaissant qui éprouve pendant des siècles et jusqu'à nous le subtil et mortifère mélange de l'arrogance et de l'autocritique. On regardera avec prudence cette ultime conclusion du livre, expliquant au fond pourquoi, en dépit ou plus certainement à cause de cet équilibre entre bonne et mauvaise conscience, «la » culture occidentale s'est révélée toujours aussi « efficace », car c'est tout de même ici la question de fond qui taraude l'auteur : quoi qu'on en dise, 
finit-il par vouloir nous convaincre, la Renaissance fut une success story, et cette histoire-là est bien à nous...

Pour souligner le propos, aucun embranchement chronologique n'est oublié, quitte à réintroduire une scansion, somme toute classique : l'héritage gréco-romain jusque vers 1000 d'abord (résumé sans surprise sous les paradigmes de la philosophie, de la ville, de la république, de l'Empire global et du droit), puis les Renaissances médiévales (chrétienne, carolingienne, scolastique, universitaire, linguistique), « l'épanouissement des possibles » de 1000 à 1400 ensuite (l'Europe sortant d'elle-même au moment où son entité géoculturelle se fissure, les débuts de la 'grande divergence' avec la Chine et l'Islam, l'humanisme italien encore et toujours, la révolution médiatique, l'expansion sur les mers), suivi par une sorte d'acmé («La réalisation des possibles 1400-1600»), écrabouillant au passage le pauvre XIV ${ }^{\mathrm{e}}$ siècle, reposant sur la trilogie "nouveaux Empires, nouveaux savoirs, nouvelles croyances" accouchant d'une "glaciation" baignée du sang des guerres et de l'exploitation. À cet endroit, force est de constater que trois métaphores, parfois usées jusqu'à la corde et logiquement liées au titre principal du livre « Le matin du monde ", structurent l'organisation de la matière : celle aérienne de l'envol ( 7 titres de chapitres), celle climatique des saisons (8 têtes de chapitre dont 4 pour l'hiver) et celle tectonique des mouvements terrestres (profondeur, haut, bas, poussée, tremblement, éruption...). On eût préféré à ce tribut peut-être inconscient payé aux paniques anthropocènes du temps une réflexion sur la périodisation et le découpage temporel puisqu'aussi bien le terme de Renaissance s'est imposé comme l'un des chrononymes les plus efficaces (ne contribue-t-il pas à tuer le Moyen Âge ?) et les plus récurrents (voir Jacques Le Goff, Faut-il découper l'histoire en tranches?, 2014).

Mais soyons juste au final : cette synthèse, qui est aussi une thèse, se laisse lire avec curiosité, tout reflet également qu'elle est d'une histoire au milieu du gué, tentée par l'écriture romanesque, le décloisonnement, la boulimie interdisciplinaire, l'hypercritique. En ce sens, et en dernier lieu, le livre parle peut-être moins pour la Renaissance que pour notre propre postmodernité.

INDEX

Index chronologique : Moyen Âge, Période moderne

Thèmes : Histoire des idées, Histoire des mentalités, Manuels/Ouvrages généraux/Outils de travail

\section{AUTEURS}

PIERRE MONNET

EHESS, Paris et IFRA-SHS, Frankfurt am Main 